\title{
Chemical Composition and Antibacterial Activity of Fractions from Bridelia micrantha Stem Bark Methanol Extract
}

\author{
Colette ElyseeAboudi Etono ${ }^{1}$, Raymond Simplice Mouokeu ${ }^{2}$, \\ Guy SedarSingor Njateng ${ }^{3}$, Alembert Tchinda Tiabou ${ }^{4}$, Rebecca Madeleine Ebelle \\ Etame $^{4}$, Rosalie Anne Ngono Ngane ${ }^{1 *}$ and MouelleSone Albert ${ }^{5}$
}

${ }^{1}$ Faculty of Sciences, University of Douala, P.O. Box 24157, Douala, Cameroon

${ }^{2}$ Institute of Fisheries and Aquatic Sciences, University of Douala, P.O. Box 7236, Douala, Cameroon

${ }^{3}$ Faculty of Sciences, University of Dschang, P.O. Box 67, Dschang, Cameroon

${ }^{4}$ Institute of Medical Research and Medicinal Plant Studies (IMPM), P.O. Box 6163, Yaoundé, Cameroon

${ }^{5}$ Faculty of Medicine and Pharmaceutical Sciences, University of Douala, P.O. Box 2701, Douala, Cameroon

*Corresponding author

K e y w o r d s
Bridelia micrantha,
Methanol extract,
Fractionation,
Antibacterial
activity,
Chromatography
Article Info
Accepted:
15 December 2019
Available Online:
20 January 2020

\section{A B S T R A C T}

Bridelia micrantha commonly known as coastal golden leaf is a member of the family Phyllanthaceae. In preliminary studies, nine fractions, named $F_{1}-F_{9}$, were obtained by fractionating the crude methanol extract of the stem bark of Bridelia micrantha using column chromatographic techniques. The $\mathrm{F}_{6}$ fraction was found to be the most active when tested for the antibacterial activity. This study is thus aimed at investigating the effect of fractionation on antibacterial activity of $F_{6}$ fraction. The $F_{6}$ fraction was fractionated by

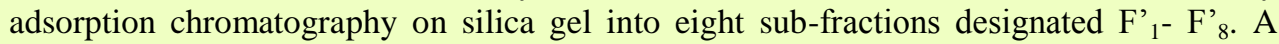
product was isolated from the dichloromethane/ methanol $(10 \%)$ fraction and the structure was determined on the basis of spectroscopic data. The antibacterial activity of the $\mathrm{F}_{6}$ fraction, sub-fractions and the product was evaluated by broth microdilution method against two reference strains and eighteen clinical bacterial strains. The chemical analysis of $\mathrm{F}_{6}$ and three sub-fractions $\mathrm{F}_{3}, \mathrm{~F}_{4}$ and $\mathrm{F}_{5}{ }_{5}$ was done using HPLC-MS. The fraction $\mathrm{F}_{6}$ exhibited strong activity on all the tested bacteria with MIC values of $128 \mu \mathrm{g} / \mathrm{ml}$ on nine strains, including Pseudomonas aeruginosa, methicillin-resistant Staphylococcus aureus, and Salmonella sp.The sub-fractions $\mathrm{F}_{4}{ }_{4}$ and $\mathrm{F}_{5}{ }_{5}$ exhibited the best activities on all the tested bacteria with MIC values of 32 to $256 \mu \mathrm{g} / \mathrm{ml}$. The chemical analysis by HPLC-MS of $\mathrm{F}_{6}, \mathrm{~F}_{3}, \mathrm{~F}_{4}$ and $\mathrm{F}_{5}{ }_{5}$ revealed the presence of almost 180 identified compounds from various classes of secondary metabolites including alkaloids, flavonoids, steroids and terpenoids. The product obtained although inactive was elucidated as Daucosterol. 


\section{Introduction}

The importance of medicinal plants in the management of human ailments cannot be over emphasized. It is clear that the plant kingdom harbors an inexhaustible source of active ingredients invaluable in the treatment of many intractable diseases (Umar et al., 2018).Plant chemistry is the basis of the therapeutic uses of herbs. A good knowledge of the chemical composition of plants leads to a better understanding of its possible medicinal value (Hussein and El-Anssary, 2018). Plants produce a good deal of secondary metabolites that have variously been shown to exhibit interesting biological and pharmacological activities (Verpoorte, 1998). Secondary plant metabolites are classified according to their chemical structures into several classes. They are expected to form new sources of antimicrobial drugs, especially against bacteria (Namita and Mukesh, 2012). Antimicrobial resistance in bacterial pathogens is a worldwide challenge leading high morbidity and mortality in clinical settings (WHO, 2014). A selected group of bacteria described by the acronym of "ESCAPE" are the most frequent bacterial agents causing severe infections with significant MDR mechanisms. The term refers to Enterococcus faecium, Staphylococcus aureus, Clostridium difficile, Acinetobacterbaumannii, Pseudomonas aeruginosa, and Enterobacteriaceae (covering all gram-negative enteric bacteria including E. coli, K. pneumonia, Proteus spp. and Enterobacter spp.) (Peterson, 2009).

A crude plant extract is a complex mixture in which compounds may interact antagonistically interfering with or masking the activity of one another(Nwodoet al., 2010). One approach to solving this problem has been to separate the compounds to greater purity and to concentrate them into fractions by various processes, including by chromatography (Jean et al., 2001). It is generally believed that fractionation of plant extracts and purification of the active principles would optimize their potencies. However, in some cases fractionation has been found to extend the spectrum of activity of plant extracts (Etame et al., 2018; Etame et al., 2019; Aboudi et al., 2019), while in others it was found to reduce the spectrum of activity (Nwodo et al., 2010), depending on whether certain constituents of the crude extract interact antagonistically, synergistically or additively when used in combination. Among the several medicinal plants distributed worldwide, Bridelia micrantha (Phyllanthaceae) is commonly used to treat several ailments including amoebic dysentery, cough, diarrhoea, gastric ulcer, eye diseases, infertility and tapeworms (Ngueyem et al., 2009; Maroyi, 2017).

Preliminary studies from our research team highlighted the antibacterial activity of the stem bark methanol extract and a significant increase of this activity achieved with an active fraction $F_{6}$ following a partition of this methanol extract and column chromatography on silica gel of the dichloromethane (DCM) portion (Aboudi et al., 2019). As a continuation to this previous work, the current study was initiated to investigate the effect of further fractionation of the active fraction $\mathrm{F}_{6}$ of $B$. micrantha stem bark methanol extract on its antibacterial activity and to analyse its chemical composition.

\section{Materials and Methods}

\section{Materials}

\section{Plant material}

Fresh barks of $B$. micrantha used in this experiment were collected in January 2017 in the Centre Region of Cameroon at Mount 
Kalla. The plant was identified at the Cameroon National Herbarium where a voucher specimen $\mathrm{N}^{\circ} 5714 \mathrm{HNC}$ (YA) was deposited.

\section{Chemicals}

Ciprofloxacin (Sigma-Aldrich, Germany) was used as reference antibiotic. $p$-Iodonitrotetrazolium chloride (Mouokeuet al., 2014) was used as microbial growth indicator.

\section{Microorganisms and Culture Media}

The antibacterial activity was carried out on two reference strains (ATCC 27853, CIP 76110) and eighteen clinical strains. The clinical strains of Escherichia coli (EC 96, EC 99, EC 136, EC 137), Enterobacter aerogenes (ENT 119, ENT 144, ENT 167), Klebsiella pneumonia (KL 111), and Staphylococcus aureus (ST 9, ST 113, ST 120) were obtained from patient suffering from gastroenteritis at the Bafang ADLUCEM hospital. Those of Salmonella enterica serovar typhi (SAL 9), Salmonella enterica serovar paratyphi B (SPB), and Salmonella enterica serovar typhimurium (STM) were obtained from the Laboratory of Bacteriology and Mycology of the "Centre Pasteur" YaoundeCameroon.

Methicillin-resistant Staphylococcus aureus strains (MRSA 3, MRSA 9, MRSA 12) were obtained from the culture collection of the Laboratory of Microbiology, Graduate School of Pharmaceutical Sciences, University of Tokyo, Japan. Multidrug resistant Providencia stuartii strain (PSNEA 16) was obtained from the culture collection of the University of Mediterranean, France. The characteristics of these bacteria were reported earlier (Aboudi et al., 2019).

\section{Methods}

\section{Plant extraction}

B. micrantha barks were collected and dried for 21 days in an ambient environment under shade and ground into powder. The powdered plant material $(2.5 \mathrm{~kg})$ was soaked in $10 \mathrm{~L}$ of methanol for 3 days. The mixture was filtered using a Whatman $\mathrm{N}^{0} 1$ filter paper and the residue was re-extracted four times as previously described. The total methanol extract was concentrated using rotatory evaporator (Heidoph). The extract was further dried in an oven (VENTI-Line) at $45^{\circ} \mathrm{C}$ for 24 hours.

\section{Fractionation of the crude extract}

The extract $(600 \mathrm{~g})$ was dissolved in a mixture of methanol $(2000 \mathrm{~mL})$, distilled water $(1000 \mathrm{~mL})$ and dichloromethane (2000mL). The DCM phase and the methanol/water phase were separated. Each phase was concentrated using a rotatory evaporator. The DCM phase (150g) was chromatographed through a silica gel (250$300 \mathrm{Mesh}$ ) as described previously (Aboudi et al., 2019). Nine fractions labeled $F_{1}$ to $F_{9}$ were obtained.

\section{Fractionation of $\mathbf{F}_{6}$ fraction}

The $\mathrm{F}_{6}$ fraction (24 g) was chromatographed through a silica gel (250-300 Mesh) column (2 cm internal diameter and $30 \mathrm{~cm}$ height) using DCM-MeOH (100:0; 95:5; 90:10; $80: 20)$ as eluent. Seventy-three fractions of $150 \mathrm{~mL}$ each were collected and concentrated using rotary evaporator at $45^{\circ} \mathrm{C}$ under reduced pressure; then they were combined on the basis of their thin layer chromatography (TLC) profiles into eight major sub-fractions labelled $\mathrm{F}_{1}{ }_{1}$ to $\mathrm{F}_{8}{ }_{8}\left(\mathrm{~F}_{1}{ }_{1}: 1-7 ; \mathrm{F}_{2}\right.$ : 8-15,17; $\mathrm{F}_{3}{ }_{3}$ : 18-25, F' ${ }_{4}: 26-35, F_{5}$ : 36-47;F' ${ }_{6}: 48-59 ; F^{\prime}{ }_{7}$ : 60-69; $\mathrm{F}_{8}:$ : 70-73). Crystals were isolated 
from the fraction 16 by recrystallizing with $\mathrm{DCM} / \mathrm{MeOH}(\mathrm{v} / \mathrm{v})$ followed by filtration. Ethyl acetate (100\%) was used to wash crystals and revelation was done with UV (254-350 $\mu \mathrm{m})$ first, then by using sulfuric acid $30 \%$. The compound obtained was labeled $\mathrm{CF}_{16}(111 \mathrm{mg})$.

\section{Antibacterial activity assay}

The in vitro antibacterial activity of the $\mathrm{F}_{6}$ fraction, sub-fractions, and the purified compound was evaluated by determining the Minimum Inhibitory Concentrations (MIC) using broth microdilution method (CLSI, 2015). Briefly, the stock solution of $F_{6}$ fraction, sub-fractions, and the purified compound was prepared with 5\% dimethylsulfoxide (DMSO) in broth culture medium. A bacterial suspension of about 1.5 x $10^{8} \mathrm{CFU} / \mathrm{ml}$ following $\mathrm{N}^{\circ} 0.5 \mathrm{McF}$ arland standard turbidity was prepared from an 18 hours old bacterial culture. These suspensions were further diluted in Mueller Hinton broth to give $1.5 \mathrm{x} 10^{6} \mathrm{CFU} / \mathrm{ml}$. The antibacterial susceptibility tests were performed in 96-well microtiter plates. A serial two-fold dilution of the $F_{6}$ fraction, sub-fractions was performed to obtain final concentrations ranging from 1024 to $8 \mu \mathrm{g} / \mathrm{ml}$ in a total volume of 100 $\mu \mathrm{l} /$ well (the final concentrations of the purified compound were ranging from 256 to $2 \mu \mathrm{g} / \mathrm{ml})$. These wells were finally inoculated with $100 \mu \mathrm{l}$ inoculum. The plates were incubated at $37^{\circ} \mathrm{C}$ for $18 \mathrm{~h}$. Following incubation, bacterial growth was monitored colorimetrically using $p$-iodonitrotetrazolium chloride (INT). Viable bacteria change the yellow dye of $p$-iodonitrotetrazolium violet into a pink colour. MIC value was recorded as the lowest concentration of the test substance that completely inhibited bacterial growth (Mouokeu et al., 2014). The antibacterial activity was classified as strong if the extract displayed a MIC value less than $500 \mu \mathrm{g} / \mathrm{ml}$, moderate from 500 to $1500 \mu \mathrm{g} / \mathrm{ml}$ and weak when over $1500 \mu \mathrm{g} / \mathrm{ml}$ (Aligiannis et al., 2001).

The Minimum Bactericidal Concentrations (MBC) were determined by adding $50 \mu \mathrm{l}$ aliquots of the preparations which did not show any growth after incubation during MIC assays to $150 \mu \mathrm{L}$ Mueller Hinton broth medium. These preparations were incubated at $37^{\circ} \mathrm{C}$ for $24 \mathrm{~h}$. The $\mathrm{MBC}$ values were regarded as the lowest concentration of extracts which did not produce any color change after addition of INT as mentioned above (Kuete et al., 2009).

The experiments were performed in duplicate and repeated three times. Ciprofloxacin (Cipro) was used as positive control while 5\% DMSO was used as negative control.

\section{HPLC-MS analysis}

HPLC was undertaken to assess the various components present in the fraction $\mathrm{F}_{6}$ and sub-fractions $\mathrm{F}_{3}{ }_{3}, \mathrm{~F}_{4}{ }_{4}, \mathrm{~F}_{5}$. High resolution mass spectra were obtained with a Q-TOF Spectrometer (Bruker, Germany) equipped with a HESI source. The spectrometer was operated in positive mode (mass range: 1001500, with a scan rate of $1.00 \mathrm{~Hz}$ ) with automatic gain control to provide highaccuracy mass measurements within 2 ppm deviation using Na-Formate as calibrant. The following parameters were used for experiments: spray voltage of $4.5 \mathrm{kV}$, capillary temperature of $200^{\circ} \mathrm{C}$. Nitrogen was used as sheath gas $(10 \mathrm{~L} / \mathrm{min})$. The spectrometer was attached to an Ultimate 3000 (Thermo Fisher, USA) HPLC system consisting of LC-pump, Diode Array Detector (DAD) $(\lambda: 215,254,280,330 \mathrm{~nm})$, auto sampler (injection volume $5 \mu \mathrm{l}$ ) and column oven $\left(50^{\circ} \mathrm{C}\right)$. The separations were performed using a synergic MAX-RP 100A (50x 2mm, $2.5 \mu \mathrm{m}$ particle size) with a $\mathrm{H}_{2} \mathrm{O}(+0.1 \%$ $\mathrm{HCOOH})(\mathrm{A}) /$ acetonitrile $(+0.1 \% \mathrm{HCOOH})$ 
(B) gradient (flow rate $500 \mu \mathrm{L} / \mathrm{min}$ ). Samples were analyzed using a gradient program as follows: $95 \%$ A isocratic for $1.5 \mathrm{~min}$, linear gradient to $100 \% \mathrm{~B}$ over $6 \mathrm{~min}$, after $100 \%$ $\mathrm{B}$ isocratic for $2 \mathrm{~min}$, the system returned to its initial condition (90\% A) within $1 \mathrm{~min}$, and was equilibrated for $1 \mathrm{~min}$.

\section{Compound structural analysis}

The chemical structure of $\mathrm{CF}_{16}$ was elucidated using spectroscopic data such as NMR 1D $\left({ }^{1} \mathrm{H},{ }^{13} \mathrm{C}, \quad \mathrm{APT}\right)$ and NMR 2D (COSY, HMBC). NMR ${ }^{13} \mathrm{C}$ data were set using HMQC experiments while fragment arrangements were done using COSY.

\section{Results and Discussion}

The increasing prevalence of antimicrobial drug-resistant microorganisms recovered from hospitalized patients is a major concern worldwide (WHO, 2014). Many strains of Staphylococcus aureus and many strains of Gram negative bacteria display multi-drug resistance (GNPIN, 2018). Because of their safety and low cost as well as their impact on a large number of microbes, medicinal plants may have the ability to treat bacterial resistance to many types of antibiotics (Hassawi and Kharma, 2006).The antimicrobial effects of extracts from a large number of plants have been evaluated and reviewed (Mouokeu et al., 2011, Ngono et al., 2011) and the mechanisms that enable the natural ingredients of herbs to resist microbes have been discussed (Montanari et al., 2012;Etame et al., 2018). The results show that these mechanisms vary greatly depending on the components of the extract (Holley and Patel, 2005); that can actually be concentrated by the means of fractionation for optimal activity.

The $\mathrm{F}_{6}$ fraction from methanol extract of $B$. micrantha stem bark, its sub-fractions, and compound were evaluated for their antibacterial activities on a panel of bacteria strains including two reference strains and eighteen clinical strains (Table 1). These results showed strong activity of the $\mathrm{F}_{6}$ fraction on all the tested bacteria with MIC values of $128 \mu \mathrm{g} / \mathrm{ml}$ on nine strains, including Pseudomonas aeruginosa, methicillinresistant Staphylococcus aureus, Enterobacter aerogenes, and Salmonella sp strains.

Previous authors reported the antibacterial activity of this plant (Steenkamp et al., 2007; Gangoué-Piéboji et al., 2009; Adefuye et al., 2011). Adefuye et al., (2011) revealed $\mathrm{MIC}_{50}$ values of ethyl acetate and acetone stem bark extract of $B$. micrantha ranged from 78 to $1250 \mu \mathrm{g} / \mathrm{ml}$ and 78 to $625 \mu \mathrm{g} / \mathrm{ml}$ respectively on Staphylococcus aureus, Shigellasonnei, Salmonella Typhimurium, and Helicobacter pylori strains.Gangoué-Piébojiet al., (2009) evaluated the antibacterial activities of $B$. micrantha methanol stem bark extract against E. coli, $P$. aeruginosa, and $S$. aureus by using agar-dilution assay. The MIC values of methanol extract against the tested bacteria were of $1250 \mu \mathrm{g} / \mathrm{mL}$. Steenkamp et al., (2007) using broth micro-dilution method found that the methanol bark extract showed MIC value of $4000 \mu \mathrm{g} / \mathrm{mL}$ against $S$. aureus. These results line up with those obtained in this work, and point out the B. micrantha barks as a source of antibacterial compounds.

After the fractionation process of the $F_{6}$ fraction, eight sub-fractions were obtained. Among them, two were ( $\mathrm{F}^{\prime}{ }_{1}$ and $\left.\mathrm{F}^{\prime}{ }_{2}\right)$ found to be inactive on all the tested bacteria; while the six others $\left(\mathrm{F}_{3}{ }_{3} \mathrm{~F}_{4}{ }_{4} \mathrm{~F}_{5}{ }_{5} \mathrm{~F}_{6}, \mathrm{~F}_{7}, \mathrm{~F}_{8}{ }_{8}\right)$ exhibited antibacterial activity with MIC values ranging from 32 to $1024 \mu \mathrm{g} / \mathrm{ml}$. F' ${ }_{3}$ showed strong activity on fifteen tested bacteria strains with MIC value of 64 to $256 \mu \mathrm{g} / \mathrm{ml}$ F' $_{4}$ and F' 5 were the most active considering their MIC value. They showed strong activity on all the twenty tested bacteria strains with MIC value 
of 64 to $256 \mu \mathrm{g} / \mathrm{ml}$ for $\mathrm{F}^{\prime}$, while MIC values of 32 to $256 \mu \mathrm{g} / \mathrm{ml}$ were obtained with $F^{\prime}$ '5. This latter was found to be more efficient on $S$. aureus sensitive clinical strains (ST9, ST113, and ST120) with MIC value of 32 $\mu \mathrm{g} / \mathrm{ml}$ (Table1). Thus from the fraction $F_{6}$ to sub-fractions $\mathrm{F}_{3}{ }_{3}, \mathrm{~F}_{4}{ }_{4}$ and $\mathrm{F}_{5}{ }_{5}$ the antibacterial activity increases. Increase antibacterial activity with fractionation reveals that the active principles of the stem barks of this plant are concentrated during fractionation in some fractions and highlights the fractionation as alternative to ameliorate plant extracts antimicrobial activity. Similar approach was reported by several authors (Khan et al., 2011; Adefuye and Ndip, 2013; Etameet al., 2019).

The sub-fractions $\mathrm{F}_{4}$ and $\mathrm{F}^{\prime}{ }_{5}$ were found to be the most active with this activity extended to methicillin-resistant Staphylococcus aureus (MRSA strains). Infections caused by MRSA are generally severe with the highest mortality rate (Cosgrove et al., 2003). Actually very few antibiotics as Lysocin E are efficient against MRSA (Hamamoto et al., 2015). The activity of these sub-fractions was extended to ESCAPE pathogens, particularly $S$. aureus, $K$. pneumonia, $P$. aeruginosa, $E$. aerogenes strains. The ESCAPE pathogens are differentiated from other pathogens due to their increased resistance to commonly used antibiotics. This increased resistance, combined with their clinical significance in the medical field, results in a necessity to combat them with novel antibiotics (Terra et al., 2018). Therefore, the sub-fractions $\mathrm{F}_{4}$ and $\mathrm{F}_{5}$ could be used directly as antibacterial or could provide molecules which could be useful as antibacterial or substrates for the synthesis of new broad spectrum antibiotics to overcome gastrointestinal tract infection bacteria.

Regarding the $\mathrm{MBC}$ values of the fractions $\mathrm{F}_{6}$ to sub-fractions $\mathrm{F}_{3}{ }_{3}, \mathrm{~F}_{4}{ }_{4}$ and $\mathrm{F}_{5}$, it was seen that $\mathrm{MBC} / \mathrm{MIC}$ ratio was less than 4 in many cases meaning that they all exerted a bactericidal activity on many of the tested organisms (Marmonier, 1990; Djeussi et al., 2013).

Figure 1

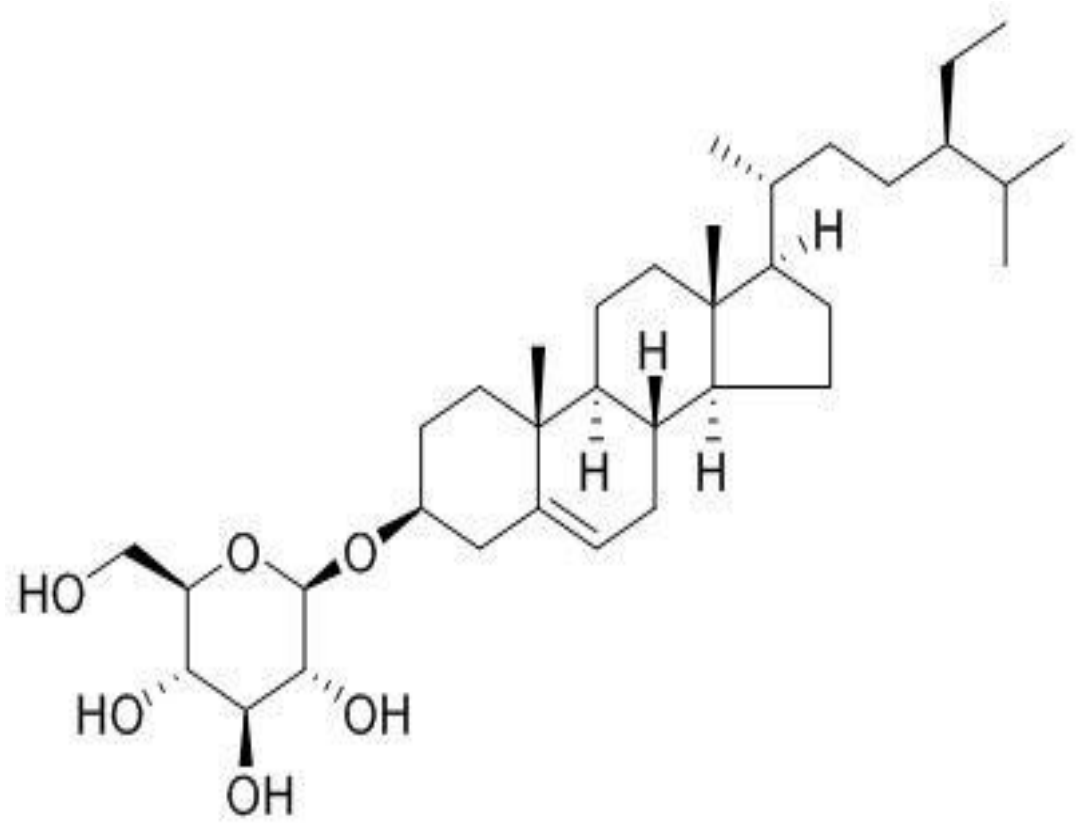


Table.1 MIC/MBC of $\mathrm{F}_{6}$ fraction and sub-fractions from the methanol extract of $B$. micrantha stem bark $(\mu \mathrm{g} / \mathrm{mL})$

\begin{tabular}{|c|c|c|c|c|c|c|c|c|c|c|c|c|c|c|c|c|}
\hline Bacteria & $\mathbf{F}_{6}$ & $\mathbf{R}$ & $F_{3}^{\prime}$ & $\mathbf{R}$ & $F_{4}^{\prime}$ & $\mathbf{R}$ & $\mathrm{F}_{5}{ }_{5}$ & $\mathbf{R}$ & $\mathrm{F}_{6}{ }_{6}$ & $\mathbf{R}$ & $F^{\prime}{ }_{7}$ & $\mathbf{R}$ & $F_{8}^{\prime}$ & $\mathbf{R}$ & Cipro & $\mathbf{R}$ \\
\hline \multicolumn{17}{|l|}{ K. pneumoniae } \\
\hline KL111 & $256 / 256$ & 1 & $512 / 512$ & 1 & $256 / 512$ & 2 & $256 / 256$ & 1 & $512 / 1024$ & 2 & $512 / 1024$ & 2 & $512 / 1024$ & 2 & $1 / 16$ & 16 \\
\hline \multicolumn{17}{|l|}{ E. aerogenes } \\
\hline ENT167 & $128 / 512$ & 4 & $512 / 1024$ & 2 & $128 / 1024$ & 8 & $128 / 1024$ & 8 & $512 /-$ & - & $512 /-$ & - & $512 /-$ & - & $8 / 128$ & 16 \\
\hline ENT144 & $256 / 256$ & 1 & $512 / 512$ & 1 & $256 / 512$ & 2 & $128 / 512$ & 4 & $256 / 1024$ & 4 & $512 / 1024$ & 2 & $512 / 1024$ & 2 & $1 /-$ & - \\
\hline ENT119 & $256 / 512$ & 2 & $256 / 512$ & 2 & $128 / 256$ & 2 & $64 / 512$ & 8 & $512 / 1024$ & 2 & $256 / 1024$ & 4 & $512 / 512$ & 1 & $1 /-$ & - \\
\hline \multicolumn{17}{|l|}{ S. aureus } \\
\hline ST9 & $128 / 512$ & 4 & $128 / 512$ & 4 & $128 / 256$ & 2 & $32 / 256$ & 8 & $128 / 1024$ & 8 & $256 / 1024$ & 4 & $256 / 1024$ & 4 & $1 / 64$ & 64 \\
\hline ST113 & $128 / 512$ & 4 & $128 / 512$ & 4 & $128 / 512$ & 4 & $32 / 512$ & 16 & $128 /-$ & - & $128 / 1024$ & 8 & $128 /-$ & - & $1 / 64$ & 64 \\
\hline ST120 & $256 / 512$ & 2 & $128 / 512$ & 4 & $64 / 512$ & 8 & $32 / 256$ & 8 & $256 / 1024$ & 4 & $512 / 1024$ & 2 & $512 / 1024$ & 2 & $8 / 128$ & 16 \\
\hline MRSA9 & $256 / 256$ & 1 & $256 / 512$ & 2 & $128 / 512$ & 4 & $128 / 256$ & 2 & $512 /-$ & - & $256 / 1024$ & 4 & $256 /-$ & - & $2 / 4$ & 2 \\
\hline MRSA3 & $128 / 256$ & 2 & $256 / 1024$ & 4 & $256 / 512$ & 2 & $256 / 256$ & 1 & $512 /-$ & - & $512 /-$ & - & $512 /-$ & - & $32 /-$ & - \\
\hline MRSA12 & $256 / 512$ & 2 & $256 / 1024$ & 4 & $128 / 512$ & 4 & $128 / 512$ & 4 & $512 / 1024$ & 2 & $1024 /-$ & - & $1024 /-$ & - & $2 / 16$ & 8 \\
\hline \multicolumn{17}{|l|}{ E. coli } \\
\hline EC96 & $128 / 512$ & 4 & $256 / 1024$ & 4 & $128 / 1024$ & 8 & $64 / 1024$ & 16 & $512 /-$ & - & $512 /-$ & - & $512 /-$ & - & $1 / 128$ & 128 \\
\hline EC99 & 256/- & - & $128 / 512$ & 4 & $128 / 512$ & 4 & $128 / 512$ & 4 & $256 / 1024$ & 4 & $256 / 1024$ & 4 & $256 / 1024$ & 4 & $4 / 16$ & 4 \\
\hline EC136 & $256 / 256$ & 1 & $256 / 512$ & 2 & $128 / 512$ & 4 & $64 / 512$ & 8 & $512 / 1024$ & 2 & $256 / 1024$ & 4 & $256 / 1024$ & 4 & $1 / 8$ & 8 \\
\hline EC137 & $128 / 256$ & 2 & $256 / 512$ & 2 & $128 / 256$ & 2 & $64 / 128$ & 2 & $256 / 1024$ & 4 & $512 / 1024$ & 2 & $512 / 1024$ & 2 & $16 / 128$ & 8 \\
\hline \multicolumn{17}{|l|}{ P. stuartii } \\
\hline PSNEA16 & $256 /-$ & - & $512 / 512$ & 1 & $128 / 512$ & 4 & $128 / 512$ & 4 & $512 / 1024$ & 2 & $256 / 1024$ & 4 & $256 / 1024$ & 4 & $1 / 16$ & 16 \\
\hline \multicolumn{17}{|l|}{ S. Typhi } \\
\hline SAL 9 & $256 /-$ & - & $256 / 512$ & 2 & $128 / 512$ & 4 & $256 / 512$ & 2 & $256 / 1024$ & 4 & $128 / 1024$ & 8 & $256 / 1024$ & 4 & $1 / 16$ & 16 \\
\hline S. typhimurium & $128 / 512$ & 4 & $64 / 1024$ & 16 & $64 / 128$ & 8 & $128 / 512$ & 4 & $256 /-$ & - & $128 /-$ & - & $128 /-$ & - & $32 / 64$ & 2 \\
\hline S. paratyphi B & $128 / 512$ & 4 & $128 / 512$ & 4 & $64 / 1024$ & 16 & $64 / 512$ & 8 & $512 / 1024$ & 2 & $1024 / 1024$ & 1 & $512 / 1024$ & 2 & $1 / 128$ & 128 \\
\hline \multicolumn{17}{|l|}{ P. aeruginosa } \\
\hline ATCC 27853 & $256 / 512$ & 2 & $512 / 512$ & 1 & $256 / 512$ & 2 & $256 / 256$ & 1 & $512 / 1024$ & 2 & $512 / 1024$ & 2 & $512 /-$ & - & $1 / 64$ & 64 \\
\hline CIP 76110 & $128 / 512$ & 4 & $64 / 512$ & 8 & $64 / 512$ & 8 & $128 / 256$ & 2 & $256 / 1024$ & 4 & $256 / 1024$ & 4 & $128 / 1024$ & 8 & $1 / 64$ & 64 \\
\hline
\end{tabular}

- = MIC or MBC that was greater than 1024 
Table.2 Isolated compounds by the HPLC-MS

\begin{tabular}{|c|c|c|c|c|c|c|}
\hline Compound name & $\begin{array}{l}\text { Chemical } \\
\text { formula }\end{array}$ & $\begin{array}{c}\mathbf{F}_{6} \\
\text { Fraction }\end{array}$ & $\begin{array}{c}F_{3}^{\prime} 3 \\
\text { Fraction }\end{array}$ & $\begin{array}{c}\text { F'}_{4} \\
\text { Fraction }\end{array}$ & $\begin{array}{c}\text { F' }_{5} \\
\text { Fraction }\end{array}$ & Compound Class \\
\hline Sacranoside A & $\mathrm{C}_{21} \mathrm{H}_{34} \mathrm{O}_{10}$ & $\checkmark$ & $\mathrm{x}$ & $\mathrm{x}$ & $\mathrm{x}$ & \\
\hline Verbenol & $\mathrm{C}_{10} \mathrm{H}_{16} \mathrm{O}$ & $\checkmark$ & $\mathrm{x}$ & $\mathrm{x}$ & $\mathrm{x}$ & \\
\hline p-Cymene & $\mathrm{C}_{10} \mathrm{H}_{14}$ & $\checkmark$ & $\mathrm{x}$ & $\mathrm{x}$ & $\mathrm{x}$ & \\
\hline Schizonepetoside C & $\mathrm{C}_{16} \mathrm{H}_{26} \mathrm{O}_{7}$ & $\checkmark$ & $\mathrm{x}$ & $\mathrm{x}$ & $\mathrm{x}$ & \\
\hline Neohancoside B & $\mathrm{C}_{21} \mathrm{H}_{36} \mathrm{O}_{11}$ & $\checkmark$ & $\mathrm{x}$ & $\mathrm{x}$ & $\mathrm{x}$ & \\
\hline Neohancoside A & $\mathrm{C}_{21} \mathrm{H}_{36} \mathrm{O}_{10}$ & $\checkmark$ & $\mathrm{x}$ & $\mathrm{x}$ & $\mathrm{x}$ & \\
\hline Thujopsadiene & $\mathrm{C}_{15} \mathrm{H}_{22}$ & $\checkmark$ & $\mathrm{x}$ & $\mathrm{x}$ & $\mathrm{x}$ & \\
\hline Widdrol & $\mathrm{C}_{15} \mathrm{H}_{26} \mathrm{O}$ & $\checkmark$ & $\mathrm{x}$ & $\mathrm{x}$ & $\checkmark$ & \\
\hline Dendroside E & $\mathrm{C}_{21} \mathrm{H}_{36} \mathrm{O}_{8}$ & $\checkmark$ & $\mathrm{x}$ & $\mathrm{x}$ & $\mathrm{x}$ & \\
\hline Dendroside $\mathbf{E}$ & $\mathrm{C}_{21} \mathrm{H}_{36} \mathrm{O}_{8}$ & $\checkmark$ & $\mathrm{x}$ & $\mathrm{x}$ & $\mathrm{x}$ & \\
\hline Trilobolide & $\mathrm{C}_{27} \mathrm{H}_{38} \mathrm{O}_{10}$ & $\checkmark$ & $\mathrm{x}$ & $\mathrm{x}$ & $\mathrm{x}$ & \\
\hline Pterosin E & $\mathrm{C}_{14} \mathrm{H}_{16} \mathrm{O}_{3}$ & $\checkmark$ & $\mathrm{x}$ & $\mathrm{x}$ & $\mathrm{x}$ & \\
\hline Ursiniolide A & $\mathrm{C}_{22} \mathrm{H}_{28} \mathrm{O}_{7}$ & $\checkmark$ & $\mathrm{x}$ & $\mathrm{x}$ & $\mathrm{x}$ & \\
\hline $\begin{array}{l}\text { 5alpha-Acetyl-5alpha- } \\
\text { decinnamoyltaxagifine }\end{array}$ & $\mathrm{C}_{30} \mathrm{H}_{40} \mathrm{O}_{13}$ & $\checkmark$ & $\mathrm{x}$ & $\mathrm{x}$ & $\mathrm{x}$ & \\
\hline Homofukinolide & $\mathrm{C}_{25} \mathrm{H}_{34} \mathrm{O}_{6}$ & $\checkmark$ & $\mathrm{x}$ & $\mathrm{x}$ & $\mathrm{X}$ & \\
\hline Vernodalin & $\mathrm{C}_{19} \mathrm{H}_{20} \mathrm{O}_{7}$ & $\mathrm{x}$ & $\mathrm{x}$ & $\mathrm{x}$ & $\checkmark$ & \\
\hline Roseoside & $\mathrm{C}_{19} \mathrm{H}_{30} \mathrm{O}_{8}$ & $\checkmark$ & $\mathrm{x}$ & $\mathrm{x}$ & $\mathrm{X}$ & \\
\hline Valerenicacid & $\mathrm{C} 15 \mathrm{H} 22 \mathrm{O} 2$ & $\mathrm{x}$ & $\mathrm{x}$ & $\mathrm{x}$ & $\checkmark$ & \\
\hline Turmerone & $\mathrm{C}_{15} \mathrm{H}_{20} \mathrm{O}$ & $\checkmark$ & $\mathrm{x}$ & $\mathrm{x}$ & $\mathrm{x}$ & \\
\hline Marioside & $\mathrm{C}_{22} \mathrm{H}_{34} \mathrm{O}_{10}$ & $\checkmark$ & $\mathrm{x}$ & $\mathrm{x}$ & $\mathrm{x}$ & \\
\hline Psilostachyin & $\mathrm{C}_{15} \mathrm{H}_{20} \mathrm{O}_{5}$ & $\mathrm{x}$ & $\checkmark$ & $\checkmark$ & $\checkmark$ & \\
\hline Oriediterpenol & $\mathrm{C}_{20} \mathrm{H}_{32} \mathrm{O}_{2}$ & $\checkmark$ & $\checkmark$ & $\mathrm{x}$ & $\checkmark$ & \\
\hline $\begin{array}{l}\text { 2,5,7-Trihydroxy-6,8-dimethyl-3-(4'- } \\
\text { methoxybenzyl)chroman-4-one }\end{array}$ & $\mathrm{C}_{19} \mathrm{H}_{20} \mathrm{O}_{6}$ & $\checkmark$ & $\mathrm{x}$ & $\mathrm{x}$ & $\mathrm{x}$ & \\
\hline Taxezopidine B & $\mathrm{C}_{26} \mathrm{H}_{38} \mathrm{O}_{10}$ & $\checkmark$ & $\mathrm{X}$ & $\mathrm{X}$ & $\mathrm{X}$ & \\
\hline
\end{tabular}




\begin{tabular}{|c|c|c|c|c|c|c|}
\hline Taxuspine W & $\mathrm{C}_{26} \mathrm{H}_{36} \mathrm{O}_{9}$ & $\checkmark$ & $\mathrm{x}$ & $\mathrm{x}$ & $\mathrm{x}$ & \multirow{26}{*}{ Terpenoids } \\
\hline Taxuyunnanine $\mathbf{E}$ & $\mathrm{C}_{33} \mathrm{H}_{42} \mathrm{O}_{12}$ & $\checkmark$ & $\mathrm{x}$ & $\mathrm{x}$ & $\mathrm{x}$ & \\
\hline Taxumairol B & $\mathrm{C}_{28} \mathrm{H}_{40} \mathrm{O}_{12}$ & $\checkmark$ & $\mathrm{x}$ & $\mathrm{x}$ & $\mathrm{x}$ & \\
\hline Shikokianin & $\mathrm{C}_{24} \mathrm{H}_{32} \mathrm{O}_{8}$ & $\checkmark$ & $\mathrm{x}$ & $\mathrm{x}$ & $\mathrm{x}$ & \\
\hline Taxumairol C & $\mathrm{C}_{28} \mathrm{H}_{38} \mathrm{O}_{11}$ & $\checkmark$ & $\mathrm{x}$ & $\mathrm{x}$ & $\mathrm{x}$ & \\
\hline Lungshengenin $\mathbf{G}$ & $\mathrm{C}_{26} \mathrm{H}_{34} \mathrm{O}_{9}$ & $\checkmark$ & $\mathrm{x}$ & $\mathrm{x}$ & $\mathrm{x}$ & \\
\hline Yadanzioside $M$ & $\mathrm{C}_{33} \mathrm{H}_{40} \mathrm{O}_{15}$ & $\checkmark$ & $\mathrm{x}$ & $\mathrm{x}$ & $\mathrm{x}$ & \\
\hline 10-Hydroxyacetylbaccatin VI & $\mathrm{C}_{37} \mathrm{H}_{46} \mathrm{O}_{15}$ & $\checkmark$ & $\mathrm{x}$ & $\mathrm{x}$ & $\mathrm{x}$ & \\
\hline Taxuspine $\mathbf{U}$ & $\mathrm{C}_{28} \mathrm{H}_{40} \mathrm{O}_{11}$ & $\checkmark$ & $\mathrm{x}$ & $\mathrm{x}$ & $\mathrm{x}$ & \\
\hline Baccatin VI & $\mathrm{C}_{37} \mathrm{H}_{46} \mathrm{O}_{14}$ & $\checkmark$ & $\mathrm{x}$ & $\mathrm{x}$ & $\mathrm{x}$ & \\
\hline Taxchin B & $\mathrm{C}_{41} \mathrm{H}_{52} \mathrm{O}_{14}$ & $\checkmark$ & $\mathrm{x}$ & $\mathrm{x}$ & $\mathrm{x}$ & \\
\hline $\begin{array}{c}\text { 9(betaH)-9-Dihydro-19-acetoxy-10- } \\
\text { deacetylbaccatin III }\end{array}$ & $\mathrm{C}_{31} \mathrm{H}_{40} \mathrm{O}_{12}$ & $\checkmark$ & $\mathrm{x}$ & $\mathrm{x}$ & $\mathrm{x}$ & \\
\hline $\begin{array}{l}\text { 13-Deacetoxy-13,15-epoxy-11(15-->1)- } \\
\text { abeo-13-epi-baccatin VI }\end{array}$ & $\mathrm{C}_{35} \mathrm{H}_{42} \mathrm{O}_{12}$ & $\checkmark$ & $\mathrm{x}$ & $\mathrm{x}$ & $\mathrm{x}$ & \\
\hline cis-Neoabienol & $\mathrm{C}_{20} \mathrm{H}_{34} \mathrm{O}$ & $\checkmark$ & $\mathrm{x}$ & $\mathrm{x}$ & $\checkmark$ & \\
\hline $\begin{array}{l}\text { 9-Deacetyl-9-benzoyl-10- } \\
\text { debenzoyltaxchinin A }\end{array}$ & $\mathrm{C}_{31} \mathrm{H}_{40} \mathrm{O}_{10}$ & $\checkmark$ & $\mathrm{x}$ & $\mathrm{x}$ & $\mathrm{x}$ & \\
\hline Taxuspine $\mathbf{O}$ & $\mathrm{C}_{26} \mathrm{H}_{36} \mathrm{O}_{10}$ & $\checkmark$ & $\mathrm{x}$ & $\mathrm{x}$ & $\mathrm{x}$ & \\
\hline Forskoditerpenoside $\mathbf{C}$ & $\mathrm{C}_{28} \mathrm{H}_{44} \mathrm{O}_{11}$ & $\checkmark$ & $\mathrm{x}$ & $\mathrm{x}$ & $\mathrm{x}$ & \\
\hline Ganolactone & $\mathrm{C}_{27} \mathrm{H}_{36} \mathrm{O}_{6}$ & $\mathrm{x}$ & $\mathrm{x}$ & $\mathrm{x}$ & $\checkmark$ & \\
\hline 3beta-Acetyl ursa-14-en-16-one & $\mathrm{C}_{32} \mathrm{H}_{50} \mathrm{O}_{3}$ & $\mathrm{x}$ & $\mathrm{x}$ & $\mathrm{x}$ & $\checkmark$ & \\
\hline Nigakilactone I & $\mathrm{C}_{21} \mathrm{H}_{28} \mathrm{O}_{6}$ & $\mathrm{x}$ & $\mathrm{x}$ & $\checkmark$ & $\checkmark$ & \\
\hline $\begin{array}{c}\text { Lup-20(29)-ene-3alpha-acetoxy-24-oic } \\
\text { acid }\end{array}$ & $\mathrm{C}_{32} \mathrm{H}_{50} \mathrm{O}_{4}$ & $\mathrm{x}$ & $\checkmark$ & $\mathrm{x}$ & $\checkmark$ & \\
\hline $\begin{array}{l}\text { 3-Hydroxy-25-norfriedel-3,1(10)-dien- } \\
\text { 2-one-30-oic acid }\end{array}$ & $\mathrm{C}_{29} \mathrm{H}_{42} \mathrm{O}_{4}$ & $\mathrm{x}$ & $\checkmark$ & $\mathrm{x}$ & $\checkmark$ & \\
\hline Camellin & $\mathrm{C}_{18} \mathrm{H}_{30} \mathrm{O}_{7}$ & $\checkmark$ & $\mathrm{x}$ & $\mathrm{x}$ & $\mathrm{x}$ & \\
\hline Sobrerol & $\mathrm{C}_{10} \mathrm{H}_{18} \mathrm{O}_{2}$ & $\checkmark$ & $\checkmark$ & $\mathrm{x}$ & $\checkmark$ & \\
\hline Hypolidemethylether & $\mathrm{C}_{21} \mathrm{H}_{26} \mathrm{O}_{3}$ & $\checkmark$ & $\mathrm{x}$ & $\mathrm{x}$ & $\mathrm{x}$ & \\
\hline Isovaleroxy-hydroxy dihydrovaltrate & $\mathrm{C}_{27} \mathrm{H}_{40} \mathrm{O}_{11}$ & $\checkmark$ & $\mathrm{x}$ & $\mathrm{x}$ & $\mathrm{x}$ & \\
\hline
\end{tabular}




\begin{tabular}{|c|c|c|c|c|c|c|}
\hline Taxuspine F & $\mathrm{C}_{28} \mathrm{H}_{38} \mathrm{O}_{10}$ & $\checkmark$ & $\checkmark$ & $\mathrm{x}$ & $\checkmark$ & \\
\hline Valerosidatum & $\mathrm{C}_{21} \mathrm{H}_{34} \mathrm{O}_{11}$ & $\checkmark$ & $\mathrm{x}$ & $\mathrm{x}$ & $\mathrm{x}$ & \\
\hline 8-(O-Methyl-p-coumaroyl)harpaside & $\mathrm{C}_{25} \mathrm{H}_{32} \mathrm{O}_{12}$ & $\checkmark$ & $\mathrm{x}$ & $\mathrm{x}$ & $\mathrm{x}$ & \\
\hline Riddelline & $\mathrm{C}_{18} \mathrm{H}_{23} \mathrm{~N} \mathrm{O}_{6}$ & $\checkmark$ & $\mathrm{x}$ & $\mathrm{x}$ & $\mathrm{x}$ & \multirow{21}{*}{ Alkaloids } \\
\hline Serratinidine & $\mathrm{C}_{18} \mathrm{H}_{28} \mathrm{~N}_{2} \mathrm{O}_{2}$ & $\checkmark$ & $\mathrm{x}$ & $\checkmark$ & $\checkmark$ & \\
\hline Securinol C & $\mathrm{C}_{13} \mathrm{H}_{17} \mathrm{~N} \mathrm{O}_{3}$ & $\checkmark$ & $\mathrm{x}$ & $\mathrm{x}$ & $\mathrm{x}$ & \\
\hline Argentine & $\mathrm{C}_{23} \mathrm{H}_{26} \mathrm{~N}_{4} \mathrm{O}_{3}$ & $\checkmark$ & $\mathrm{x}$ & $\mathrm{x}$ & $\mathrm{x}$ & \\
\hline Ervadivaricatine A & $\mathrm{C}_{43} \mathrm{H}_{56} \mathrm{~N}_{4} \mathrm{O}_{5}$ & $\mathrm{x}$ & $\mathrm{x}$ & $\mathrm{x}$ & $\checkmark$ & \\
\hline $\begin{array}{l}\text { 1beta,2beta,5alpha,11-Tetraacetoxy- } \\
\text { 8alpha-benzoyl-4alpha-hydroxy- } \\
\text { 7beta-nicotinoyl-dihydroagarofuran }\end{array}$ & $\mathrm{C}_{36} \mathrm{H}_{41} \mathrm{~N} \mathrm{O}_{14}$ & $\mathrm{x}$ & $\mathrm{x}$ & $\mathrm{x}$ & $\checkmark$ & \\
\hline $\begin{array}{l}\text { 3-O-Tetradecanoyl-1-cyano-2-methyl- } \\
\text { 1,2-propene }\end{array}$ & $\mathrm{C}_{19} \mathrm{H}_{33} \mathrm{~N} \mathrm{O}_{2}$ & $\checkmark$ & $\checkmark$ & $\mathrm{x}$ & $\checkmark$ & \\
\hline Wilsonine & $\mathrm{C}_{20} \mathrm{H}_{25} \mathrm{~N} \mathrm{O}_{4}$ & $\mathrm{X}$ & $\mathrm{x}$ & $\mathrm{x}$ & $\checkmark$ & \\
\hline Nor-orixine & $\mathrm{C}_{16} \mathrm{H}_{19} \mathrm{~N} \mathrm{O}_{6}$ & $\checkmark$ & $\mathrm{x}$ & $\mathrm{x}$ & $\mathrm{x}$ & \\
\hline Chelirubine & $\mathrm{C}_{21} \mathrm{H}_{16} \mathrm{~N} \mathrm{O}_{5}$ & $\mathrm{x}$ & $\checkmark$ & $\mathrm{x}$ & $\checkmark$ & \\
\hline Dihydrokoumine & $\mathrm{C}_{20} \mathrm{H}_{24} \mathrm{~N}_{2} \mathrm{O}$ & $\mathrm{x}$ & $\mathrm{x}$ & $\mathrm{x}$ & $\checkmark$ & \\
\hline $\begin{array}{l}\text { N-Methyltyramine-O-alpha-L- } \\
\text { rhamnopyranoside }\end{array}$ & $\mathrm{C}_{15} \mathrm{H}_{23} \mathrm{~N} \mathrm{O}_{5}$ & $\checkmark$ & $\mathrm{x}$ & $\mathrm{x}$ & $\mathrm{x}$ & \\
\hline Pseudobrucine & $\mathrm{C}_{23} \mathrm{H}_{26} \mathrm{~N}_{2} \mathrm{O}_{5}$ & $\checkmark$ & $\mathrm{x}$ & $\mathrm{X}$ & $\mathrm{x}$ & \\
\hline Euoverrine A & $\mathrm{C}_{48} \mathrm{H}_{51} \mathrm{~N} \mathrm{O}_{18}$ & $\checkmark$ & $\checkmark$ & $\checkmark$ & $\checkmark$ & \\
\hline Subaphyllin & $\mathrm{C}_{14} \mathrm{H}_{20} \mathrm{~N}_{2} \mathrm{O}_{3}$ & $\checkmark$ & $\mathrm{x}$ & $\mathrm{x}$ & $\mathrm{x}$ & \\
\hline Aldohypaconitine & $\mathrm{C}_{33} \mathrm{H}_{43} \mathrm{~N} \mathrm{O}_{11}$ & $\checkmark$ & $\mathrm{x}$ & $\mathrm{x}$ & $\mathrm{x}$ & \\
\hline Ergocornine & $\mathrm{C}_{31} \mathrm{H}_{39} \mathrm{~N}_{5} \mathrm{O}_{5}$ & $\checkmark$ & $\mathrm{x}$ & $\mathrm{x}$ & $\mathrm{x}$ & \\
\hline Geniculine & $\mathrm{C}_{34} \mathrm{H}_{47} \mathrm{~N} \mathrm{O}_{11}$ & $\checkmark$ & $\mathrm{x}$ & $\mathrm{x}$ & $\mathrm{x}$ & \\
\hline Teixidol & $\mathrm{C}_{28} \mathrm{H}_{40} \mathrm{O}_{10}$ & $\checkmark$ & $\mathrm{x}$ & $\mathrm{x}$ & $\mathrm{x}$ & \\
\hline Thalicmine & $\mathrm{C}_{21} \mathrm{H}_{23} \mathrm{~N} \mathrm{O}_{5}$ & $\checkmark$ & $\mathrm{x}$ & $\mathrm{x}$ & $\checkmark$ & \\
\hline Lysergamide & $\mathrm{C}_{16} \mathrm{H}_{17} \mathrm{~N}_{3} \mathrm{O}$ & $\checkmark$ & $\mathrm{x}$ & $\mathrm{x}$ & $\checkmark$ & \\
\hline
\end{tabular}




\begin{tabular}{|c|c|c|c|c|c|c|}
\hline 12-Methoxyaffinisine & $\mathrm{C}_{21} \mathrm{H}_{26} \mathrm{~N}_{2} \mathrm{O}_{2}$ & $\checkmark$ & $\mathrm{X}$ & $\mathrm{x}$ & $\mathrm{x}$ & \multirow{30}{*}{$\begin{array}{l}\text { Phenolic } \\
\text { compounds }\end{array}$} \\
\hline Voacamine & $\mathrm{C}_{43} \mathrm{H}_{52} \mathrm{~N}_{4} \mathrm{O}_{5}$ & $\checkmark$ & $\mathrm{X}$ & $\mathrm{x}$ & $\mathrm{x}$ & \\
\hline Terminaline & $\mathrm{C}_{23} \mathrm{H}_{41} \mathrm{~N} \mathrm{O}_{2}$ & $\checkmark$ & $\checkmark$ & $\mathrm{x}$ & $\mathrm{x}$ & \\
\hline Camptothecin & $\mathrm{C}_{20} \mathrm{H}_{16} \mathrm{~N}_{2} \mathrm{O}_{4}$ & $\checkmark$ & $\checkmark$ & $\mathrm{x}$ & $\checkmark$ & \\
\hline 11-Deoxojervine & $\mathrm{C}_{27} \mathrm{H}_{41} \mathrm{~N} \mathrm{O}_{2}$ & $\checkmark$ & $\checkmark$ & $\mathrm{x}$ & $\mathrm{x}$ & \\
\hline Germerine & $\mathrm{C}_{37} \mathrm{H}_{59} \mathrm{~N} \mathrm{O}_{11}$ & $\checkmark$ & $\checkmark$ & $\mathrm{x}$ & $\mathrm{x}$ & \\
\hline Buxbodine D & $\mathrm{C}_{28} \mathrm{H}_{46} \mathrm{~N}_{2} \mathrm{O}$ & $\checkmark$ & $\mathrm{x}$ & $\mathrm{x}$ & $\mathrm{x}$ & \\
\hline Parasorbicacid & $\mathrm{C}_{6} \mathrm{H}_{8} \mathrm{O}_{2}$ & $\checkmark$ & $\checkmark$ & $\mathrm{x}$ & $\checkmark$ & \\
\hline Danshensu & $\mathrm{C}_{6} \mathrm{H}_{10} \mathrm{O}_{5}$ & $\checkmark$ & $\checkmark$ & $\mathrm{x}$ & $\checkmark$ & \\
\hline 2-Hexenyl benzoate & $\mathrm{C}_{13} \mathrm{H}_{16} \mathrm{O}_{2}$ & $\mathrm{x}$ & $\mathrm{x}$ & $\mathrm{x}$ & $\checkmark$ & \\
\hline Phenethylcaffeate & $\mathrm{C}_{17} \mathrm{H}_{16} \mathrm{O}_{4}$ & $\checkmark$ & $\mathrm{x}$ & $\mathrm{x}$ & $\mathrm{x}$ & \\
\hline 6'-O-Methylhonokiol & $\mathrm{C}_{19} \mathrm{H}_{20} \mathrm{O}_{2}$ & $\checkmark$ & $\mathrm{x}$ & $\mathrm{x}$ & $\checkmark$ & \\
\hline Protocatechuoylcalleryanin & $\mathrm{C}_{20} \mathrm{H}_{22} \mathrm{O}_{11}$ & $\checkmark$ & $\checkmark$ & $\mathrm{x}$ & $\checkmark$ & \\
\hline 6-Shogaol & $\mathrm{C}_{17} \mathrm{H}_{24} \mathrm{O}_{3}$ & $\mathrm{x}$ & $\mathrm{x}$ & $\mathrm{x}$ & $\checkmark$ & \\
\hline 4-Prenyl dihgdropinosylvin & $\mathrm{C}_{19} \mathrm{H}_{22} \mathrm{O}_{2}$ & $\mathrm{x}$ & $\checkmark$ & $\checkmark$ & $\checkmark$ & \\
\hline Thelephantin $\mathrm{C}$ & $\mathrm{C}_{32} \mathrm{H}_{30} \mathrm{O}_{9}$ & $\mathrm{x}$ & $\checkmark$ & $\mathrm{x}$ & $\checkmark$ & \\
\hline Salicylic acid & $\mathrm{C}_{7} \mathrm{H}_{6} \mathrm{O}_{3}$ & $\mathrm{x}$ & $\checkmark$ & $\mathrm{x}$ & $\checkmark$ & \\
\hline Tropolone & $\mathrm{C}_{7} \mathrm{H}_{6} \mathrm{O}_{2}$ & $\mathrm{x}$ & $\checkmark$ & $\mathrm{x}$ & $\checkmark$ & \\
\hline Vanillyl alcohol & $\mathrm{C}_{8} \mathrm{H}_{10} \mathrm{O}_{3}$ & $\mathrm{x}$ & $\checkmark$ & $\mathrm{x}$ & $\checkmark$ & \\
\hline Pyrogallol & $\mathrm{C}_{6} \mathrm{H}_{6} \mathrm{O}_{3}$ & $\checkmark$ & $\mathrm{x}$ & $\mathrm{x}$ & $\mathrm{x}$ & \\
\hline Phenyl-2-propanone & $\mathrm{C}_{9} \mathrm{H}_{10} \mathrm{O}$ & $\mathrm{x}$ & $\checkmark$ & $\checkmark$ & $\checkmark$ & \\
\hline alpha-Thujaplicin & $\mathrm{C}_{10} \mathrm{H}_{12} \mathrm{O}_{2}$ & $\mathrm{x}$ & $\mathrm{x}$ & $\mathrm{x}$ & $\checkmark$ & \\
\hline 9,12-Dihydroxy-15-nonadecenoic acid & $\mathrm{C}_{19} \mathrm{H}_{36} \mathrm{O}_{4}$ & $\checkmark$ & $\mathrm{x}$ & $\checkmark$ & $\checkmark$ & \\
\hline Palmitoleicacid & $\mathrm{C}_{16} \mathrm{H}_{30} \mathrm{O}_{2}$ & $\checkmark$ & $\checkmark$ & $\mathrm{x}$ & $\checkmark$ & \\
\hline Valerenolicacid & $\mathrm{C}_{16} \mathrm{H}_{24} \mathrm{O}_{2}$ & $\checkmark$ & $\mathrm{x}$ & $\checkmark$ & $\checkmark$ & \\
\hline 9,10-Dihydroxystearic acid & $\mathrm{C}_{18} \mathrm{H}_{36} \mathrm{O}_{4}$ & $\checkmark$ & $\checkmark$ & $\mathrm{x}$ & $\checkmark$ & \\
\hline Methyl 9-octadecenoate & $\mathrm{C}_{19} \mathrm{H}_{36} \mathrm{O}_{2}$ & $\checkmark$ & $\checkmark$ & $\mathrm{x}$ & $\checkmark$ & \\
\hline Trichosanicacid & $\mathrm{C}_{18} \mathrm{H}_{30} \mathrm{O}_{2}$ & $\checkmark$ & $\checkmark$ & $\checkmark$ & $\checkmark$ & \\
\hline Hydnocarpicacid & $\mathrm{C}_{16} \mathrm{H}_{28} \mathrm{O}_{2}$ & $\mathrm{x}$ & $\checkmark$ & $\mathrm{x}$ & $\checkmark$ & \\
\hline Ethyloctadecanoate & $\mathrm{C}_{20} \mathrm{H}_{40} \mathrm{O}_{2}$ & $\mathrm{x}$ & $\checkmark$ & $\mathrm{x}$ & $\checkmark$ & \\
\hline
\end{tabular}




\begin{tabular}{|c|c|c|c|c|c|c|}
\hline Nilicacid & $\mathrm{C}_{5} \mathrm{H}_{10} \mathrm{O}_{3}$ & $\mathrm{x}$ & $\mathrm{X}$ & $\mathrm{x}$ & $\checkmark$ & \multirow{7}{*}{ Fatty acids } \\
\hline 4,8,12-Trimethyl tridecanoic acid & $\mathrm{C}_{16} \mathrm{H}_{32} \mathrm{O}_{2}$ & $\mathrm{x}$ & $\checkmark$ & $\mathrm{x}$ & $\checkmark$ & \\
\hline Coronaricacid & $\mathrm{C}_{18} \mathrm{H}_{32} \mathrm{O}_{3}$ & $\mathrm{x}$ & $\mathrm{x}$ & $\mathrm{x}$ & $\checkmark$ & \\
\hline Docosandioicacid & $\mathrm{C}_{22} \mathrm{H}_{42} \mathrm{O}_{4}$ & $\mathrm{x}$ & $\mathrm{x}$ & $\mathrm{x}$ & $\checkmark$ & \\
\hline Tetradecenoicacid C & $\mathrm{C}_{14} \mathrm{H}_{26} \mathrm{O}_{2}$ & $\mathrm{x}$ & $\checkmark$ & $\mathrm{x}$ & $\checkmark$ & \\
\hline Gadoleicacid & $\mathrm{C}_{20} \mathrm{H}_{38} \mathrm{O}_{2}$ & $\mathrm{x}$ & $\mathrm{x}$ & $\mathrm{x}$ & $\checkmark$ & \\
\hline Eucalyptus wax & $\mathrm{C}_{33} \mathrm{H}_{64} \mathrm{O}_{2}$ & $\checkmark$ & $\mathrm{x}$ & $\mathrm{x}$ & $\mathrm{x}$ & \\
\hline Sarcostin & $\mathrm{C}_{21} \mathrm{H}_{34} \mathrm{O}_{6}$ & $\checkmark$ & $\mathrm{x}$ & $\mathrm{x}$ & $\mathrm{x}$ & \multirow{12}{*}{ Steroids } \\
\hline Strophanthidin & $\mathrm{C}_{23} \mathrm{H}_{32} \mathrm{O}_{6}$ & $\checkmark$ & $\mathrm{x}$ & $\mathrm{x}$ & $\mathrm{x}$ & \\
\hline Bufotalin & $\mathrm{C}_{25} \mathrm{H}_{34} \mathrm{O}_{7}$ & $\checkmark$ & $\mathrm{x}$ & $\mathrm{x}$ & $\mathrm{x}$ & \\
\hline Taccalonolide $\mathbf{H}$ & $\mathrm{C}_{36} \mathrm{H}_{44} \mathrm{O}_{14}$ & $\checkmark$ & $\mathrm{x}$ & $\mathrm{x}$ & $\mathrm{x}$ & \\
\hline $\begin{array}{l}\beta \text { - sitosterol 3-O- } \beta \text { - D- } \\
\text { glucopyranoside }\end{array}$ & $\mathrm{C}_{35} \mathrm{H}_{60} \mathrm{O}_{6}$ & $\checkmark$ & $\mathrm{X}$ & $\mathrm{x}$ & $\mathrm{x}$ & \\
\hline Cinobufagin & $\mathrm{C}_{26} \mathrm{H}_{34} \mathrm{O}_{6}$ & $\checkmark$ & $\checkmark$ & $\checkmark$ & $\checkmark$ & \\
\hline $\begin{array}{c}\text { 1,4-Epoxy-16-hydroxyheneicos- } \\
\text { 1,3,12,14-tetraene }\end{array}$ & $\mathrm{C}_{21} \mathrm{H}_{34} \mathrm{O}_{2}$ & $\checkmark$ & $\checkmark$ & $\mathrm{x}$ & $\mathrm{X}$ & \\
\hline 5beta-Cholanic acid & $\mathrm{C}_{24} \mathrm{H}_{40} \mathrm{O}_{2}$ & $\checkmark$ & $\checkmark$ & $\mathrm{x}$ & $\checkmark$ & \\
\hline Sengosterone & $\mathrm{C}_{29} \mathrm{H}_{44} \mathrm{O}_{9}$ & $\checkmark$ & $\mathrm{X}$ & $\mathrm{x}$ & $\mathrm{x}$ & \\
\hline 4-Methyl-7-ergosta-8,24(28)-diene & $\mathrm{C}_{29} \mathrm{H}_{48}$ & $\checkmark$ & $\checkmark$ & $\mathrm{x}$ & $\mathrm{x}$ & \\
\hline Stigmasta-4,25-dien-3beta,6beta-diol & $\mathrm{C}_{29} \mathrm{H}_{48} \mathrm{O}_{2}$ & $\checkmark$ & $\mathrm{x}$ & $\mathrm{x}$ & $\mathrm{x}$ & \\
\hline 25R-Spirost-4-en-3,12-dione & $\mathrm{C}_{27} \mathrm{H}_{38} \mathrm{O}_{4}$ & $\mathrm{x}$ & $\mathrm{x}$ & $\mathrm{x}$ & $\checkmark$ & \\
\hline Flavaspidinin & $\mathrm{C}_{23} \mathrm{H}_{30} \mathrm{O}_{8}$ & $\checkmark$ & $\mathrm{x}$ & $\mathrm{x}$ & $\mathrm{x}$ & \multirow{8}{*}{ Flavonoids } \\
\hline 3,5-Diacetyltambulin & $\mathrm{C}_{22} \mathrm{H}_{20} \mathrm{O}_{9}$ & $\mathrm{x}$ & $\checkmark$ & $\checkmark$ & $\checkmark$ & \\
\hline Retusine & $\mathrm{C}_{16} \mathrm{H}_{25} \mathrm{~N} \mathrm{O}_{5}$ & $\checkmark$ & $\mathrm{x}$ & $\mathrm{x}$ & $\mathrm{x}$ & \\
\hline Agastachin & $\mathrm{C}_{47} \mathrm{H}_{44} \mathrm{O}_{22}$ & $\checkmark$ & $\checkmark$ & $\mathrm{x}$ & $\mathrm{x}$ & \\
\hline Triacetylhispidulin & $\mathrm{C}_{22} \mathrm{H}_{18} \mathrm{O}_{9}$ & $\mathrm{x}$ & $\mathrm{x}$ & $\mathrm{x}$ & $\checkmark$ & \\
\hline Ergochrysin & $\mathrm{C}_{31} \mathrm{H}_{28} \mathrm{O}_{14}$ & $\mathrm{x}$ & $\mathrm{x}$ & $\mathrm{x}$ & $\checkmark$ & \\
\hline Mulberrofuran Q & $\mathrm{C}_{34} \mathrm{H}_{24} \mathrm{O}_{10}$ & $\mathrm{x}$ & $\checkmark$ & $\mathrm{x}$ & $\checkmark$ & \\
\hline Theasinensin A & $\mathrm{C}_{44} \mathrm{H}_{34} \mathrm{O}_{22}$ & $\mathrm{x}$ & $\mathrm{x}$ & $\mathrm{x}$ & $\checkmark$ & \\
\hline
\end{tabular}




\begin{tabular}{|c|c|c|c|c|c|c|}
\hline $\begin{array}{c}\text { Methyl-3-O-beta-D-glucopyranosyl } \\
\text { polygalacate }\end{array}$ & $\mathrm{C}_{37} \mathrm{H}_{60} \mathrm{O}_{11}$ & $\mathrm{x}$ & $\mathrm{x}$ & $\mathrm{x}$ & $\checkmark$ & \multirow{5}{*}{ Glucosides } \\
\hline Coelovirin $A$ & $\mathrm{C}_{21} \mathrm{H}_{30} \mathrm{O}_{12}$ & $\checkmark$ & $\mathrm{x}$ & $\mathrm{x}$ & $\mathrm{x}$ & \\
\hline $\begin{array}{l}\text { 1,1'-Dibenzene-6',8',9'-trihydroxy-3- } \\
\text { allyl-4-O-beta-D-glucopyranoside }\end{array}$ & $\mathrm{C}_{24} \mathrm{H}_{30} \mathrm{O}_{9}$ & $\checkmark$ & $\mathrm{x}$ & $\mathrm{x}$ & $\mathrm{x}$ & \\
\hline Tetracentronside B & $\mathrm{C}_{26} \mathrm{H}_{32} \mathrm{O}_{11}$ & $\checkmark$ & $\mathrm{x}$ & $\mathrm{x}$ & $\mathrm{x}$ & \\
\hline Magnoshinin & $\mathrm{C}_{24} \mathrm{H}_{30} \mathrm{O}_{6}$ & $\checkmark$ & $\mathrm{x}$ & $\checkmark$ & $\checkmark$ & \\
\hline Sterekunthal B & $\mathrm{C}_{20} \mathrm{H}_{18} \mathrm{O}_{4}$ & $\checkmark$ & $\mathrm{x}$ & $\mathrm{x}$ & $\mathrm{x}$ & \multirow{4}{*}{$\begin{array}{l}\text { Phtalide } \\
\text { derivatives }\end{array}$} \\
\hline Theaspirone & $\mathrm{C}_{13} \mathrm{H}_{20} \mathrm{O}_{2}$ & $\checkmark$ & $\mathrm{x}$ & $\mathrm{x}$ & $\checkmark$ & \\
\hline Senkyunolide K & $\mathrm{C}_{12} \mathrm{H}_{16} \mathrm{O}_{3}$ & $\checkmark$ & $\checkmark$ & $\mathrm{x}$ & $\mathrm{x}$ & \\
\hline Senkyunolide M & $\mathrm{C}_{16} \mathrm{H}_{22} \mathrm{O}_{4}$ & $\mathrm{x}$ & $\checkmark$ & $\mathrm{x}$ & $\checkmark$ & \\
\hline Adenine & $\mathrm{C}_{5} \mathrm{H}_{5} \mathrm{~N}_{5}$ & $\checkmark$ & $\checkmark$ & $\mathrm{x}$ & $\mathrm{x}$ & \multirow{3}{*}{ Purines } \\
\hline Hypoxanthine & $\mathrm{C}_{5} \mathrm{H}_{4} \mathrm{~N}_{4} \mathrm{O}$ & $\mathrm{x}$ & $\mathrm{x}$ & $\mathrm{x}$ & $\checkmark$ & \\
\hline Zeatin & $\mathrm{C}_{10} \mathrm{H}_{13} \mathrm{~N}_{5} \mathrm{O}$ & $\mathrm{x}$ & $\mathrm{x}$ & $\mathrm{x}$ & $\checkmark$ & \\
\hline Prenylcaffeate & $\mathrm{C}_{14} \mathrm{H}_{16} \mathrm{O}_{4}$ & $\checkmark$ & $\mathrm{x}$ & $\mathrm{x}$ & $\mathrm{x}$ & \multirow[t]{2}{*}{ Coumarins } \\
\hline 6-Hydroxy-7-methylesculetin & $\mathrm{C}_{10} \mathrm{H}_{8} \mathrm{O}_{3}$ & $\checkmark$ & $\mathrm{x}$ & $\mathrm{x}$ & $\mathrm{x}$ & \\
\hline Quassimarin & $\mathrm{C}_{26} \mathrm{H}_{34} \mathrm{O}_{11}$ & $\checkmark$ & $\checkmark$ & $\mathrm{x}$ & $\mathrm{x}$ & \multirow{2}{*}{ Quassinoids } \\
\hline Picrasinoside $\mathbf{C}$ & $\mathrm{C}_{28} \mathrm{H}_{42} \mathrm{O}_{11}$ & $\checkmark$ & $\mathrm{x}$ & $\mathrm{x}$ & $\mathrm{x}$ & \\
\hline alpha:beta-Diolein & C39 H72 O5 & $\mathrm{x}$ & $\checkmark$ & $\mathrm{x}$ & $\checkmark$ & \multirow{2}{*}{ Diglycerides } \\
\hline Glyceride-1,3-dipalmito-2-sorbate & C41 H74 O5 & $\mathrm{x}$ & $\checkmark$ & $\mathrm{x}$ & $\checkmark$ & \\
\hline Phycocyanobiline & $\mathrm{C}_{33} \mathrm{H}_{36} \mathrm{~N}_{4} \mathrm{O}_{6}$ & $\checkmark$ & $\mathbf{x}$ & $\mathbf{x}$ & $\mathbf{x}$ & \multirow{2}{*}{ Bile pigments } \\
\hline Biliverdin & $\mathrm{C}_{33} \mathrm{H}_{34} \mathrm{~N}_{4} \mathrm{O}_{6}$ & $\checkmark$ & $\mathrm{x}$ & $\mathrm{x}$ & $\mathrm{x}$ & \\
\hline 3-Methylcyclotridecan-1-one & $\mathrm{C}_{14} \mathrm{H} 26 \mathrm{O}$ & $\mathrm{x}$ & $\checkmark$ & $\mathrm{x}$ & $\checkmark$ & \multirow{2}{*}{ Ketone } \\
\hline Civetone & $\mathrm{C}_{17} \mathrm{H}_{30} \mathrm{O}$ & $\mathrm{x}$ & $\mathrm{x}$ & $\mathrm{x}$ & $\checkmark$ & \\
\hline Maesaquinone & $\mathrm{C} 26 \mathrm{H} 42 \mathrm{O} 4$ & $\checkmark$ & $\mathrm{x}$ & $\mathrm{x}$ & $\mathrm{x}$ & \multirow[t]{2}{*}{ Quinones } \\
\hline Methylenetanshinquinone & C18 H14 O3 & $\checkmark$ & $\mathrm{x}$ & $\mathrm{x}$ & $\mathrm{x}$ & \\
\hline Isoallylbenzene & $\mathrm{C}_{9} \mathrm{H}_{10}$ & $\checkmark$ & $\checkmark$ & $\checkmark$ & $\checkmark$ & \multirow[t]{2}{*}{ Hydrocarbures } \\
\hline 1-Propenyl-cyclohexane & $\mathrm{C}_{9} \mathrm{H}_{16}$ & $\mathrm{x}$ & $\checkmark$ & $\mathrm{x}$ & $\checkmark$ & \\
\hline
\end{tabular}




\begin{tabular}{|c|c|c|c|c|c|c|}
\hline Exaltolide & $\mathrm{C}_{15} \mathrm{H}_{28} \mathrm{O}_{2}$ & $\checkmark$ & $\mathrm{x}$ & $\mathrm{x}$ & $\mathrm{x}$ & Macrolide \\
\hline Adenosine & $\mathrm{C}_{10} \mathrm{H}_{13} \mathrm{~N}_{5} \mathrm{O}_{4}$ & $\checkmark$ & $\checkmark$ & $\checkmark$ & $\checkmark$ & Nucleoside \\
\hline Muricatacin & $\mathrm{C}_{17} \mathrm{H}_{32} \mathrm{O}_{3}$ & $\checkmark$ & $\checkmark$ & $\mathrm{x}$ & $\checkmark$ & Acetogenin \\
\hline $\begin{array}{c}\text { (2S)-1-O-(9Z,12Z-Octadeca-dien- } \\
\text { noyl)-3-O-beta-D-galactopyranosyl- } \\
\text { glycerol }\end{array}$ & $\mathrm{C}_{27} \mathrm{H}_{48} \mathrm{O}_{9}$ & $\checkmark$ & $\mathrm{x}$ & $\mathrm{x}$ & $\mathrm{x}$ & Glycerolipid \\
\hline Suaveolol & $\mathrm{C}_{20} \mathrm{H}_{34} \mathrm{O}_{2}$ & $\checkmark$ & $\mathrm{x}$ & $\mathrm{x}$ & $\mathrm{x}$ & $\begin{array}{l}\text { Polycyclic } \\
\text { compound }\end{array}$ \\
\hline Wilforonide & $\mathrm{C}_{13} \mathrm{H}_{16} \mathrm{O}_{3}$ & $\mathrm{x}$ & $\mathrm{x}$ & $\mathrm{x}$ & $\checkmark$ & Keto-ester \\
\hline Deoxymorellin & $\mathrm{C}_{33} \mathrm{H}_{38} \mathrm{O}_{6}$ & $\checkmark$ & $\checkmark$ & $\mathrm{x}$ & $\checkmark$ & Miscellenous \\
\hline Yonogenin & $\mathrm{C}_{27} \mathrm{H}_{44} \mathrm{O}_{4}$ & $\checkmark$ & $\mathrm{x}$ & $\mathrm{x}$ & $\checkmark$ & Saponin \\
\hline Urushiol III & $\mathrm{C}_{21} \mathrm{H}_{32} \mathrm{O}_{2}$ & $\mathrm{x}$ & $\checkmark$ & $\mathrm{x}$ & $\checkmark$ & Cathecol \\
\hline $\begin{array}{l}\text { 3beta-Methoxy-9beta,19-cyclolanost- } \\
\text { 23(E)-en-25,26-diol }\end{array}$ & $\mathrm{C}_{31} \mathrm{H}_{52} \mathrm{O}_{3}$ & $\mathrm{x}$ & $\checkmark$ & $\mathrm{x}$ & $\checkmark$ & Vitamin (Vit E) \\
\hline $\begin{array}{c}\text { 8-Methyl-5-isopropyl-6,8-nonadiene-2- } \\
\text { one }\end{array}$ & $\mathrm{C}_{12} \mathrm{H}_{22} \mathrm{O}$ & $\mathrm{x}$ & $\mathrm{x}$ & $\mathrm{x}$ & $\checkmark$ & Ether \\
\hline 6-Phenylundecane & $\mathrm{C}_{17} \mathrm{H}_{28}$ & $\mathrm{x}$ & $\mathrm{x}$ & $\mathrm{x}$ & $\checkmark$ & Alkylbenzene \\
\hline Sandaracopimarinol & $\mathrm{C}_{20} \mathrm{H}_{32} \mathrm{O}$ & $\mathrm{x}$ & $\mathrm{x}$ & $\mathrm{x}$ & $\checkmark$ & Phenanthrene \\
\hline 5-Methoxy-1,7-diphenyl-3-heptanone & $\mathrm{C}_{20} \mathrm{H}_{24} \mathrm{O}_{2}$ & $\mathrm{x}$ & $\mathrm{x}$ & $\mathrm{x}$ & $\checkmark$ & diarylheptanoid \\
\hline Spatheliabischromene & $\mathrm{C}_{20} \mathrm{H}_{20} \mathrm{O}_{4}$ & $\checkmark$ & $\mathrm{x}$ & $\mathrm{x}$ & $\mathrm{x}$ & Benzopyranoid \\
\hline Icaride $\mathbf{A 2}$ & $\mathrm{C}_{22} \mathrm{H}_{28} \mathrm{O}_{9}$ & $\checkmark$ & $\mathrm{x}$ & $\mathrm{x}$ & $\mathrm{x}$ & Phenylpropanoid \\
\hline Margaspidin & $\mathrm{C}_{24} \mathrm{H}_{30} \mathrm{O}_{8}$ & $\checkmark$ & $\mathrm{x}$ & $\mathrm{x}$ & $\mathrm{x}$ & $\begin{array}{c}\text { Phloroglucinol } \\
\text { derivative }\end{array}$ \\
\hline Shikonofuran C & $\mathrm{C}_{21} \mathrm{H}_{26} \mathrm{O}_{5}$ & $\checkmark$ & $\mathrm{x}$ & $\mathrm{x}$ & $\mathrm{x}$ & Shikonin derivative \\
\hline
\end{tabular}




\section{Identification of isolated compound}

The structure of the compound $\mathrm{CF}_{16}$ was determined on the basis of spectral data. This structure was confirmed by comparing with those described in literature (Moradkhaniet al., 2014). By comparison of the data with those reported in the literature, the compound was identified as Daucosterol ( $\beta$ - sitosterol 3O- $\beta$ - D- glucopyranoside) (Fig. 1). It has a molecular weight of $576 \mathrm{~g} / \mathrm{mol}$, corresponding to the empirical formula $\mathrm{C}_{35} \mathrm{H}_{60} \mathrm{O}_{6}$.

The isolated compound was found to be inactive on all the tested bacteria. These results are similar to those reported by Bayor et al., (2009) who evaluated $\beta$-sitosterol-3-OD-glucopyranoside on $S$. aureus, B. subtilis, E. coli, $P$. aeruginosa and it had no antibacterial effect. Njinga et al., (2016) reported a good activity of the molecule on a set of bacteria including S.aureus and E.coli, with MIC ranged from 25 to $50 \mu \mathrm{g} / \mathrm{ml}$. This different result could be due to the fact that Njinga et al., used just a loop of a 0,5 McFarland bacterial solution as the inoculum; this is very low comparing to that we used in our work.

\section{HPLC-MS analysis}

The chemical analysis of the $\mathrm{F}_{6}$ fraction, the sub-fractions $\mathrm{F}_{3}{ }_{3}, \mathrm{~F}_{4}{ }_{4}$ and $\mathrm{F}_{5}{ }_{5}$ revealed the presence of almost 180 identified compounds from various classes of secondary metabolites including alkaloids, flavonoids, phenols, quinones, steroids and terpenoids (Table 2). These phytochemicals may explain their antibacterial capacity, since the inhibitory properties of these secondary metabolites against different pathogens have been reported (Cowan, 1999). For example, flavonoids inhibit the activity of enzymes by forming complexes with bacterial cell walls, extracellular and soluble proteins. More lipophilic flavonoids disrupt cell wall integrity (Kurtz et al., 1994). The chemical analysis revealed that many compounds that had not been detected in the $\mathrm{F}_{6}$ fraction were found in the sub-fractions, suggesting that their concentration increased during the fractionation process. This may explain the increased antibacterial ability of sub-fractions $\mathrm{F}_{3}, \mathrm{~F}^{\prime}{ }_{4}$ and $\mathrm{F}_{5}{ }_{5}$ compared to the $\mathrm{F}_{6}$ fraction.

In conclusion, the results revealed an increased activity with fractionation, the subfractions $\mathrm{F}_{4}{ }_{4}$ and $\mathrm{F}_{5}$ being the most active. These sub-fractions could be used as sources of antibacterial compounds.

\section{References}

Aboudi, E.C.E., Mouokeu, R.S., Njateng, G.S.S., Tchinda, T.A., Etame, R.E. Rosalie Anne Ngono, N.A.R. 2019.Antibacterial Activity of Methanol Extract and Fractions from Stem Bark of Bridelia micrantha (Hochst.)Baill. (Phyllanthaceae). EC Pharmacology and Toxicology. 7(7): 609-616.

Adefuye, A. and Ndip, R. N. 2013. Phytochemical analysis and antibacterial evaluation of the ethyl acetate extract of the stem bark of Brideliamicrantha. Pharmacognosy Magazine. 9: 45-50.

Adefuye, A.O., Samie, A., Ndip, R.N. 2011. "In Vitro evaluation of the antimicrobial activity of extracts of Bridelia micrantha on selected bacterial pathogens". Journal of Medicinal Plants Research. 5: 5116-5122.

Algiannis, N., Kalpotzakis, E., Mitaku, S., Chinou, I.B. 2001. Composition and antimicrobial activity of the essential oils of two Origanum species. Journal of Agricultural and Food Chemistry. 40: 4168-4170.

Bayor, M.T., Gbedema, S.Y., Anna, K. 2009. The antimicrobial activity of Croton membranaceus, a species used in 
formulations for measles in Ghana. $J$ Pharmacogn Phytother. 1:47-51.

Clinical and Laboratory Standard Institute (CLSI). 2015. Methods for dilution antimicrobial susceptibility tests for bacteria that grow aerobically approved standard. 9th edition, 35(2):1-15.

Cosgrove, S.E., Sakoulas, G., Perencevich, E.N., Schwaber, M.J., Karchmer, A.W., Carmeli, Y. 2003. Comparison of mortality associated with methicillinresistant and methicillin susceptible Staphylococcus aureus bacteremia meta- analysis. Clin. Infect. Dis. 36: 5359.

Cowan, M.M. 1999. Plant products as antimicrobial agents. Clinical Microbiology Reviews. 12: 564-582.

Djeussi, E., Noumedem, A.K., Seukep, J.A., Fankam, A.G., Voukeng, K.I., Tankeo S.B., Nkuete, H.L., Kuete, V.2013. Antibacterial activities of selected edible plants extracts against multidrugresistant Gram-negative bacteria. BMC Complementary and Alternative Medicine. 13: 164.

Etame, R.E., Mouokeu, R.S., Pouaha, C.L.C., Kenfack, I. V., Tchientcheu, R., Assam, J.P.A., Monthe, P. F.S., Tchinda, A.T., Etoa, F.X., Kuiate, J.R., Ngono, N.R.A. 2018. Effect of Fractioning on Antibacterial Activity of Enantia chlorantha Oliver (Annonaceae) Methanol Extract and Mode of Action. Evidence-Based Complementary and Alternative Medicine. Article ID 4831593, 13 pages.

Etame, R.M.E., Mouokeu, R.S., Monthe, P.F.S., Voukeng, K.I., Cidjeu, P.L.C., Tchinda, T.A., Yaya, G.A.J., Ngono, N.A.R, Kuiate, R.J., Etoa, F.X. 2019.Effect of fractioning on antibacterial activity of n-butanol fraction from Enantia chlorantha stem bark methanol extract. BMC Complementary and Alternative
Medicine.19:56

Jean, A.A., Robert, P.B., Quirico, J., Nelson, Z., Giselle, T., Guy, H.H. 2001. Separation of crude plant extracts with high speed CCC for primary screening in drug discovery. J. Liquid Chromatogr. Related Technol. 24 (11 \& 12): 1827-1840.

Gangoué-Piéboji, J., Eze, N., Djintchui, A.N., Ngameni, B., Tsabang, N., Pegnyemb, D.E., Biyiti, L., Ngassam, P., KoullaShiro, S., Galleni, M. 2009. The in vitro antimicrobial activity of some traditionally used medicinal plants against beta-lactam-resistant bacteria. $J$. Infect. Dev. Ctries. 3: 671-680.

Groupe National de Guidance en matière de Prévention des Infections Nosocomiales (GNPIN). 2018. Recommandations Nationales pour la lutte contre le Staphylococcus Aureus Résistant à la Méticilline (Methicilline Resistant Staphylococcus aureus) dans les établissements hospitaliers. Luxembourg.

Hamamoto, H., Urai, M., Ishii, K., Yasukawa, J., Paudel, A., Murai, M., Kaji, T., Kuranaga, T., Hamase, K., Katsu, T., Su, J., Adachi, T., Uchida, R., Tomoda, H., Yamada, M., Souma, M., Kurihara, H., Inoue, M., Sekimizu, K. 2015. Lysocin $\mathrm{E}$ is a new antibiotic that targets menaquinone in the bacterial membrane. Nature Chemical Biology. 11(2): 127-133.

Holley, R. and Patel, D. 2005. Improvement in shelf-life and safety of perishable foods by plant essential oils and smoke antimicrobials. Food Microbiology. 22: 273-292.

Hussein, R. A., El-Anssary, A. A. 2018. Plants Secondary Metabolites: The Key Drivers of the Pharmacological Actions of Medicinal Plants.

Khan, M.A.A., Islam, M.T., Rahman, M. A., Ahsan, Q. 2011. Antibacterial activity 
of diff erent fractions of Commelina benghalensis L. Der Pharmacia Sinica, Pelagia Research Library. 2(2): 320 326.

Kharma, A. and Hassawi, D. S. 2006: The Genetic Relationship and Antimicrobial Activity of Plantago species Against Pathogenic Bacteria. World Journal of Agricultural Sciences. 2(3): 311-318.

Kuete, V., Fozing, D.C., Kapche W.F., Mbaveng, A.T., Keumedjio, F., Ngadjui, B.T. 2009. Antimicrobial activity of the methanolic extract and compounds from Morus mesozygia stem bark. Journal of Ethnopharmacology. 124: 551-555.

Kurtz, M.B., Heath, I.B., Marrinan, J., Dreikhorn, S., Onishi, J., Douglas, C. 1994. Morphological effects of lipopeptides against Aspergillus fumigatus correlate with activities against (1,3)-beta-D-glucan synthase. Antimicrob Agents Chem 38(7): 14801489.

Maroyi, A., 2017. Ethnopharmacology and Therapeutic Value of Bridelia micrantha (Hochst.) Baill. in Tropical Africa: A Comprehensive Review. Molecules, 22(9).

Montanari, B. 2012. A critical analysis of the introduction of essential oil distillation in the High Atlas of Morocco with reference to the role of gendered traditional knowledge ( $\mathrm{PhD}$ thesis) University of Kent, UK: School of Anthropology and conservation.

Moradkhani, S., Kobarfard, F., Ayatollahi, S.A.M. 2014. Phytochemical Investigations on Chemical Constituents of Achillea tenuifolia Lam. Iranian Journal of Pharmaceutical Research, 13(3): 1049-1054.

Mouokeu, R.S., Njateng, G.S., Ngono, N.A., Kuiate, J.R., Kamtchueng, M.O. 2014. Antifungal and antioxidant activity of Crassocephalum bauchiense (Hutch.)
Milne-Redh ethyl acetate extract and fractions (Asteraceae). BMC Research Notes.7: 244

Mouokeu, R. S., Ngono, R. A. N., Lunga, P. K., Koanga, M. M., Tiabou, A. T., Njateng, G.S.S., Tamokou, J. D.D., Kuiate, J-R. 2011. Antibacterial and dermal toxicological profles of ethyl acetate extract from Crassocephalum bauchiense (Hutch.) Milne-Redh (Asteraceae). BMC Complementary and Alternative Medicine.11(43).

Namita, P. and Mukesh, R. 2012. Medicinal plants used as antimicrobial agents: a review. Int. Res. J. Pharm. 3: 31-40.

Ngono, N. R. A., Koanga, M. M. L., Tchinda, T. A., Magnifouet, N. H., Motso, C. P. R., Mballa, B. Z., Ebelle, E. R. M., Ndifor, F., Biyiti, L., Amvam, Z. P. H. 2011. Ethnobotanical survey of some Cameroonian plants used for treatment of viral diseases. African Journal of Plant Science. 5(1): 15-21.

Ngueyem, T.A., Brusotti, G., Caccialanza, G., Finzi, P.V. 2009. The genus Bridelia: A phytochemical and ethnopharmacological review. $J$. Ethnopharmacol.12: 339-349.

Njinga, N.S., Sule, M.I., Pateh, U.U., Hassan H.S., Abdullahi, S.T.,Ache, R.N. 2016. Isolation and Antimicrobial Activity of $\beta$-Sitosterol-3-OGlucoside from Lannea Kerstingii Engl. \& K. Krause (Anacardiacea). Nitte University Journal of Health Science. 6(1).

Nwodo, U.U., Ngene, A.A., Iroegbu, C.U. 2010.Effects of Fractionation on Antibacterial Activity of Crude Extracts of Tamarindus indica. Afr. J. Biotechnol. 9: 7108-7113.

Peterson, L.R. 2009. Bad bugs, no drugs: no ESCAPE revisited. Clin Infect Dis. 49: 992.

Steenkamp, V., A.C. Fernandes and C.E. van Rensburg, 2007. Antibacterial activity of Venda medicinal plants. Fitoterapia, 
78: 561-564.

Terra, L., Dyson, P.J., Hitchings, M.D., Thomas, L., Abdelhameed, A., Banat, I.M., Gazze, S.A., Vujaklija, D., Facey, P.D., Francis, L.W., Quinn, G.A. 2018. A Novel Alkaliphilic Streptomyces Inhibits ESKAPE Pathogens. Frontiers in Microbiology.

Umar, Z., Qureshi, A.S., Usman, M., Sarfraz, A., Umar, S., Umar, T., Hussain, M. 2018. Response of dietary supplementation of black seed (Nigella sativa) oil on hematological parameters, serum biochemistry and reproductive hormones in male rabbits. Academia Publishing. 6(9): 276-280.

Verpoorte, R. 1998. Exploration of nature's chemodiversity: The role of secondary metabolites as leads in drug development. Drug Dev. Trends. 3: 232-233.

World Health Organization (WHO).2014. Antimicrobial Resistance. Global Report on Surveillance.

\section{How to cite this article:}

Colette ElyseeAboudi Etono, Raymond Simplice Mouokeu, Guy SedarSingor Njateng, Alembert Tchinda Tiabou, Rebecca Madeleine Ebelle Etame, Rosalie Anne Ngono Ngane and MouelleSone Albert. 2020. Chemical Composition and Antibacterial Activity of Fractions from Bridelia micrantha Stem Bark Methanol Extract. Int.J.Curr.Microbiol.App.Sci. 9(01): 11021119. doi: https://doi.org/10.20546/ijcmas.2020.901.125 